\title{
Influence of Lubricant Inclusion on the Rheological Behaviour and Residence Time Distribution of Ethylene Vinyl Acetate Copolymer during Single Screw Extrusion
}

\author{
I. Aydin*, E.B. Eker, U. Yalman And A. Durmus \\ Istanbul University - Cerrahpasa, Engineering Faculty, Department of Chemical Engineering, Rheology \\ Laboratory, Avcilar Campus, Avcilar 34320, Istanbul, Turkey
}

\begin{abstract}
The general purpose of this study is to investigate the effect of lubricant inclusion on the rheological behaviour and residence time of polymeric materials during single screw extrusion. The residence time distribution was consequently calculated by means of "styrofoam-particulate tracer method" developed for our experiments including the single screw extrusion of ethylene vinyl acetate copolymer coated with stearic acid used as the lubricant. Tests were performed and data were reported for three different screw speeds performed at $70^{\circ} \mathrm{C}$ operating temperature value.
\end{abstract}

DOI: 10.12693/APhysPolA.135.862

PACS/topics: rheology, polymer processing flows, extrusion, single screw, residence time

\section{Introduction}

The plasticating extruder is probably the most widely used unit operation in the polymers industry and the mixing conditions, flow patterns and residence time distribution (RTD) in a plasticating extruder have significant effects on the product, especially when polymers sensitive to heat are extruded or when good mixing of additives is required. The rotational speed of the screw, the temperature of the screw and the barrel section as the process parameters have an effect on the RTD of the extruder [1]. The residence time distribution in an industrial extruder is extremely important from the point of view of quality control of the extruded material. The optimization of extrusion process depends, to a great extent, on the ability to predict the influence of the extrusion parameters on RTD [2].

This paper is a part of an ongoing project that aims to in situ visualize the polymer flow during extrusion process. An instrumented visual barrel system is developed in this project to assist the modeling and optimization of the single screw extrusion process. Rheological flow of studied material and the whole plasticating process (including solid conveying, melting and melt conveying) could be clearly observed and the process was enabled to be recorded behind the transparent barrel by means of cameras. A case study, where an ethylene vinyl acetate copolymer (EVA) used as the polymeric material and stearic acid used as the lubricant were extruded by means of aforementioned set up and details, was presented together with the conclusion of results obtained, in the later part of the paper.

\footnotetext{
* corresponding author; e-mail: i.aydin@istanbul.edu.tr
}

\section{Experimental procedure}

In the first part of the experimental study, polymer resin was coated with a lubricant material in order to observe the lubricating effect on the extrusion process. The pristine and coated polymer were then extruded at $70^{\circ} \mathrm{C}$ extrusion temperature while varying the screw rotation speeds of 50,60 and $70 \mathrm{rpm}$. The residence time data were obtained, and necessary numerical calculations were performed for the discussion and comparison of the extrusion performance of the material used under different extrusion parameters together with the lubricating effect.

\subsection{Materials and preparation of coated polymer resin}

An ethylene-vinyl acetate (EVA) copolymer resin (Elvax 40W, DuPont ${ }^{\circledR}$, Belgium) with vinyl acetate comonomer content of $40 \mathrm{wt} \%$ (density $=0.965 \mathrm{~g} / \mathrm{cm}^{3}$, melting point $=47^{\circ} \mathrm{C}$ ) was used as received. Stearic acid $\left(\right.$ density $=0.9408 \mathrm{~g} / \mathrm{cm} 3$, melting point $\left.=69.3^{\circ} \mathrm{C}\right)$ used as a lubricant was provided by Hangsun (Maleysia). Methanol (Emsure ${ }^{\circledR}$, Merck with density $=0.792 \mathrm{~g} / \mathrm{cm}^{3}$, boiling point $=64.5^{\circ} \mathrm{C}$ and vapor pressure $=12.8 \mathrm{kPa}$ at $20^{\circ} \mathrm{C}$ ) was preferred as a solvent to coat surfaces of granules of EVA with the stearic acid used as a lubricant. Stearic acid coated EVA samples were obtained by first dissolving various amounts of stearic acid in $100 \mathrm{~g}$ methanol at $40{ }^{\circ} \mathrm{C}$ in order to obtain stearic acid/EVA blends with different weight percents and then mixing for 10 minutes. After mixing, appropriate amount of ethylene vinly acetate copolymer were added into the solutions and mixed manually for 30 minutes. At the end of the vaporization, stearic acid/EVA blends were obtained. In this paper, only the results for $7.5 \mathrm{wt} \%$ stearic acid coated EVA sample were presented. 
In order to use as a particulate tracer material, a styrofoam (EPS 100, bead size range $0.4-0.7 \mathrm{~mm}$, sieve analysis $0.4-0.8 \mathrm{~mm}$ minimum $99 \%$, density $\approx 615 \mathrm{~kg} / \mathrm{m}^{3}$ ) was obtained from Ravago Petrokimya, (Turkey); it was used as received.

\subsection{Extruder system for in-situ flow visualisation and measuring procedure}

A specially designed single screw plasticating extruder with a transparent barrel was used for visualising material flow via tracer (styrofoam) particulates and also collecting samples for RTD calculations. Details of this setup were given elsewhere [3]. The barrel of this extruder used throughout this study is composed of transparent glass which is resistant to thermal shocks.

In the current investigations, one screw geometry was used with the diameter and $\mathrm{L} / \mathrm{D}$ ratio values being $15 \mathrm{~mm}$ and 29, respectively. For this screw configuration, the rotor speeds of 50, 60 and $70 \mathrm{rpm}$ were then randomly assigned.

The RTD was measured using the particulate tracer material (coloured where necessary). Once steady state condition was achieved on the extruder as indicated by constant temperature after feeding the polymer material, the tracer material was added from the hopper of the extruder. After each collection of samples, they were pressed into the circular film form. Measurement of the tracer concentration, $c$, in these films was performed and recorded as a function of time. Residence time distribution, $E(t)$, and the mean residence time, $\tau$, were calculated using the data. The mathematical relationships for each one of the terms are as follows:

$$
\begin{aligned}
& E(t)=\frac{c(t)}{\int_{0}^{\infty} c(t) \mathrm{d} t} \\
& \tau=\int_{0}^{\infty} t E(t) \mathrm{d} t
\end{aligned}
$$

\section{Results and discussion}

\subsection{Residence time}

Residence time distributions for the pristine EVA and stearic acid coated EVA (7.5 wt\%) are depicted in Fig. 1a and b. As may be seen from Fig. 1a for the pristine EVA that the maximum $E(t)$ peak value for $50 \mathrm{rpm}$ is 0.0182 at 70 seconds, for $60 \mathrm{rpm}$ is 0.0190 at 60 seconds and for $70 \mathrm{rpm}$ is 0.0195 at 50 seconds. The mean residence time, $\tau[\mathrm{s}]$, values measured for the pristine EVA are tabulated in Table I. As may be seen from Fig. 1b for the stearic acid coated EVA ( $7.5 \mathrm{wt} \% \mathrm{SA} / \mathrm{EVA})$ that the maximum $E(t)$ peak value for $50 \mathrm{rpm}$ is 0.0186 at 60 seconds, for $60 \mathrm{rpm}$ is 0.0195 at 50 seconds and for $70 \mathrm{rpm}$ is 0.0200 at 40 seconds. The mean residence time, $\tau$ [s], values measured for the $7.5 \mathrm{wt} \%$ stearic acid coated EVA are tabulated in Table I.

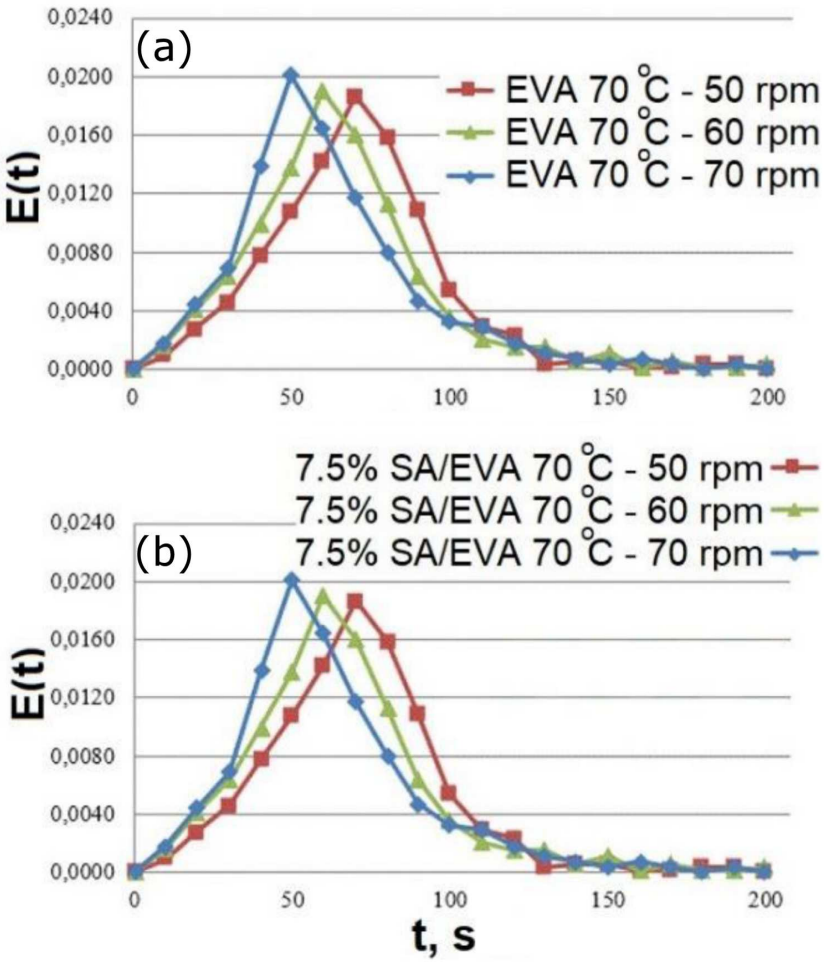

Fig. 1. Residence time distribution of (a) only EVA, (b) $7.5 \% \mathrm{SA} / \mathrm{EVA}$ at $50-60-70 \mathrm{rpm}$ screw speeds for $70^{\circ} \mathrm{C}$ extrusion temperature value.

TABLE I

The mean residence time, $\tau[\mathrm{s}]$, values measured for the EVA and $7.5 \mathrm{wt} \% \mathrm{SA} / \mathrm{EVA}$ samples at $70{ }^{\circ} \mathrm{C}$ extrusion temperature value

\begin{tabular}{c|c|c}
\hline \hline $\begin{array}{c}\text { Screw } \\
\text { speed [rpm] }\end{array}$ & $\begin{array}{c}\tau \text { for only } \\
\text { EVA }[\mathrm{s}]\end{array}$ & $\begin{array}{c}\tau \text { for } 7.5 \mathrm{wt} \% \\
\text { SA/EVA }[\mathrm{s}]\end{array}$ \\
\hline 50 & 70.3 & 64.0 \\
60 & 65.8 & 59.1 \\
70 & 61.9 & 55.5
\end{tabular}

\section{Conclusion}

The flow rate of polymer increases with the rotation speed of the extruder screw. Hence, it may be seen from Table I that the characteristic residence time decreases with the increasing of screw speed. This is consistent that an increase of the screw rotation speed make the viscosity decrease and thus favors the flowing of the polymer.

It was observed during the tests performed with the current extruder set up that tracing elements had almost characteristic residence times and stable flow characteristics along the feeding and pumping (melt conveying) zones while the total RTD of the polymer material in the extruder depends mainly on the flow mechanisms in the melt conveying zone. 


\section{Acknowledgments}

This work was supported by Scientific Research Projects Coordination Unit of Istanbul University. Project number 20956.

\section{References}

[1] D. Wolf, D.H. White, AIChE Journal 22, 122 (1976).

[2] Z. Kemblowski, J. Sek, Poly. Eng. Sci. 21, 1194 (1981).

[3] E.B. Eker, M.Sc. Thesis, Chemical Engineering Department, Engineering Faculty, Istanbul University, Istanbul 2017. 